\title{
Victimization and psychopathic features in a population-based sample of Finnish adolescents
}

\section{Saukkonen, Suvi}

2016-10

Saukkonen, S , Aronen , E T , Laajasalo, T , Salmi , V , Kivivuori , J \& Jokela , M 2016 , '

Victimization and psychopathic features in a population-based sample of Finnish adolescents ' , Child Abuse and Neglect, vol. 60 , pp. 58-66 . https://doi.org/10.1016/j.chiabu.2016.09.008

http://hdl.handle.net/10138/228901

https://doi.org/10.1016/j.chiabu.2016.09.008

publishedVersion

Downloaded from Helda, University of Helsinki institutional repository.

This is an electronic reprint of the original article.

This reprint may differ from the original in pagination and typographic detail.

Please cite the original version. 


\title{
Victimization and psychopathic features in a population-based sample of Finnish adolescents
}

\author{
Suvi Saukkonen ${ }^{\mathrm{a}, *}$, Eeva T. Aronen ${ }^{\mathrm{a}}$, Taina Laajasalo ${ }^{\mathrm{b}, \mathrm{c}}$, Venla Salmi ${ }^{\mathrm{d}}$, \\ Janne Kivivuori ${ }^{\mathrm{d}}$, Markus Jokela ${ }^{\mathrm{c}}$ \\ a University of Helsinki and Helsinki University Hospital, Children's Hospital, Child Psychiatry, Helsinki, Finland \\ b Forensic Psychology Center for Children and Adolescents, Children's Hospital, Child Psychiatry, Helsinki University Hospital, Helsinki, \\ Finland \\ ${ }^{c}$ Institute of Behavioural Sciences, University of Helsinki, Helsinki, Finland \\ d Institute of Criminology and Legal Policy, Criminological Unit, University of Helsinki, Helsinki, Finland
}

\section{A R T I C L E I N F O}

\section{Article history:}

Received 16 April 2016

Received in revised form 12 August 2016

Accepted 18 September 2016

Available online 28 September 2016

\section{Keywords:}

Adolescence

Victimization

Psychopathic features

\begin{abstract}
A B S T R A C T
We examined different forms of victimization experiences in relation to psychopathic features and whether these associations differed in boys and girls among 4855 Finnish school adolescents aged 15-16 years. Psychopathic features were measured with the Antisocial Process Screening Device- Self Report (APSD-SR). Victimization was assessed with questions about violent and abusive experiences across lifetime and within the last 12 months. Results from linear regression analysis showed that victimization was significantly associated with higher APSD-SR total scores, more strongly in girls than boys. Recent (12-month) victimization showed significance in the relationship between victimization and psychopathic features; especially recent sexual abuse and parental corporal punishment were strong determinants of higher APSD-SR total scores. The present study demonstrates novel findings on how severe victimization experiences relate to psychopathic features in community youth, especially in girls. The findings underscore the need for comprehensive evaluation of victimization experiences when psychopathic features are present in youth.
\end{abstract}

(c) 2016 Elsevier Ltd. All rights reserved.

\section{Introduction}

Psychopathy is viewed as a constellation of affective, interpersonal, and behavioral features such as callousness, shallow emotions, lack of empathy, grandiosity, manipulativeness, and persistent violation of social norms (Forth, Kosson, \& Hare, 2003). In the past two decades, psychopathic features in youth have been a highly studied topic as clinicians and researchers have begun to trace the development of psychopathy in adolescence and childhood (Rubio, Krieger, Finney, \& Coker, 2014). Although the construct of psychopathy is well-established in adult literature, the extension of psychopathy to youth and children is controversial (Rubio et al., 2014), and carries a potential for misuse and harm when used improperly (Forth et al., 2003). As full-fledged psychopathy does not manifest in childhood or adolescence, it is more appropriate to examine continuously varying psychopathic features instead of clinical diagnosis when studying child and adolescent populations (Loeber, Burke, \& Pardini, 2009). Correlates of psychopathic features in youth and children may offer significant insights in

\footnotetext{
* Corresponding author at: Children's Hospital, University of Helsinki and Helsinki University Hospital, Tukholmankatu 8C 613, Helsinki 00290, Finland.

E-mail address: suvi.saukkonen@helsinki.fi (S. Saukkonen).
} 
understanding the development of adult psychopathy, and for designing more individualized and effective interventions, as well as facilitating preventive efforts.

Psychopathy has typically been conceptualized as a homogeneous construct, however, several researchers have posited that there may be distinct variants of psychopathy that potentially have different developmental pathways (Poythress \& Skeem, 2005; Skeem, Poythress, Edens, Lilienfeld, \& Cale, 2003). Already in the 1940's, Karpman theorized that "primary" psychopathy is characterized by an innate or heritable affective deficit, whereas "secondary" psychopathy develops more as a consequence of adaptation to environmental factors such as parental rejection, abuse, or trauma (Karpman, 1941, 1948). To date, a substantial amount of research supports Karpman's model; individuals scoring high on psychopathy measures can be meaningfully divided into two groups on the basis of the level of anxiety, impulsivity, and history of abuse. Thus, it seems that the "secondary group" show higher levels of anxiety (Hicks, Markon, Patrick, Krueger, \& Newman, 2004; Kimonis, Skeem, Cauffman, \& Dmitrieva, 2011; Skeem, Johansson, Andershed, Kerr, \& Louden, 2007; Tatar, Cauffman, Kimonis, \& Skeem, 2012; Vaughn, Edens, Howard, \& Smith, 2009) and impulsivity (Hicks et al., 2004) and a greater history of childhood abuse and trauma (Hicks, Vaidyanathan, \& Patrick, 2010; Kimonis et al., 2011; Tatar et al., 2012; Vaughn et al., 2009) than the "primary group" in studies of both adult and youth offenders.

On the other hand, it has also been argued that abuse and victimization might not influence the development of psychopathy (Blair, Peschardt, Budhani, Mitchell, \& Pine, 2006). In their review, Blair et al. (2006) suggest that abuse is unlikely to bring about the affective "flattening" that is thought to be the core feature of psychopathy. Indeed, there are studies showing that abuse is not associated with psychopathy, whereas low parental care (especially maternal care) and poor parental attachment are more significantly associated with psychopathic features (Gao, Raine, Chan, Venables, \& Mednick, 2010; Kimonis, Cross, Howard, \& Donoghue, 2013). The aforementioned inconsistent findings highlight the importance of further research on how victimization experiences relate to psychopathic features.

While childhood abuse may contribute to the development of adult psychopathy, children and adolescent exposed to severe maltreatment or abuse may manifest features that are similar to psychopathic traits, but are not connected to the adult psychopathy construct at a functional level (Odgers, Reppucci, \& Moretti, 2005). For example, abused children and adolescents may suppress their emotional responses as an adaptive coping mechanism (Porter, 1996). Thus, the experiences of harsh life and severe victimization may result into interpersonal disposition and interaction style that resembles psychopathic traits (e.g. callousness and lacking remorse), but are not linked in the same way to the latent construct (Odgers et al., 2005).

Most studies on the topic have focused on youth offenders (Campbell, Porter, \& Santor, 2004; Krischer \& Sevecke, 2008; Odgers et al., 2005), and less is known about psychopathic features in victimized adolescents in the general population. There are only few community-based studies on bullying/aggression and juvenile psychopathic features (Docherty, Boxer, Huesmann, O'Brien, \& Bushman, 2015; Fanti \& Kimonis, 2012; Fanti, Demetriou, \& Kimonis, 2013; Kimonis, Centifanti, Allen, \& Frick, 2014), but these studies have not compared how such different forms of victimization (including also severe forms of abuse) are related to psychopathic traits among community youth. Also, there may be gender differences in the developmental pathways to psychopathy (Rubio et al., 2014). Traumatic experiences are considered more important risk factors for aggressive behavior in girls than in boys (Chamberlain \& Moore, 2002). Furthermore, the prevalence of traumatization appears to be heightened among female juvenile offenders compared with males (Abram et al., 2004; Cauffman, Feldman, Waterman, \& Steiner, 1998; Dixon, Howie, \& Starling, 2004). Very few studies have investigated psychopathic features in abused or victimized girls (Fanti \& Kimonis, 2012; Hemphala \& Hodgins, 2014; Krischer \& Sevecke, 2008; Odgers et al., 2005) and the results from these studies have been contradicting.

The inconsistent findings on victimization and psychopathic features in youth highlight the need for further research on the topic. Our study aim to examine victimization experiences in relation to psychopathic features in a nationally representative sample of community youth. Based on the literature above, we hypothesize that adolescents who have experiences victimization show psychopathic features. In addition, we aim to explore whether (1) the severity of victimization, (2) gender, and (3) timing of victimization (lifetime vs. 12-month victimization) have a potential influence on the association between victimization and psychopathic features.

\section{Method}

\subsection{Participants and procedure}

The present study draws on the Finnish Self-Report Delinquency Study 2012 (FSRD-12) data. The FSRD-12 is a series of nationally representative self-report surveys of juvenile delinquency consisting of a variety of questions regarding delinquent behavior, and a set of background factors including both individual and family-level variables as well as personality features. The FSRD-12 was carried out in spring 2012 randomly in 51 municipal comprehensive schools where all 9th grade (15-16-year-old) students were asked to participate in the study. Classification criteria comprised geographical area and community residential density. Participation to the study was voluntary and of the targeted 6089 students, $80 \%$ completed the questionnaire, resulting in a final sample of 4855 students ( 2378 boys, 2477 girls). The questionnaire was completed anonymously via computer during a regular class supervised by a trained teacher. Reasons for non-response were personal (e.g. illness, athletic meet, family vacation, or truancy) or a poor net connection randomly occurring in some schools. As the participation to the study was voluntary and the questionnaire anonymous, in accordance with the regulations of the 
Finnish Advisory Board of Research Integrity, no ethical nor parents' approval was required for the study. The questionnaire contained information how to contact someone in case the participant was in trouble or felt the need to discuss about something with an adult. Descriptions of the survey system, procedure, and sampling are presented in detail elsewhere (Kivivuori \& Bernburg, 2011; Laajasalo et al., 2014; Salmi, 2012). The measures of the present study were included in the FSRD-12 and are described in the following.

\subsection{Measures}

\subsubsection{Dependent variable.}

2.2.1.1. The Antisocial Process Screening Device-Self Report (APSD-SR). Deriving from the measure of adult psychopathy, the Psychopathy Checklist - Revised (Hare, 1991), the APSD was developed to measure early manifestations of the traits associated with psychopathy in children and adolescents (Frick \& Hare, 2001). The APSD consists of 20 items with each item scored on a 3 -point scale $(0=$ not at all true, $1=$ sometimes true, and $2=$ definitely true). Although a relatively brief measure, the APSD is one of the most extensively utilized and tested measures of psychopathic features in children and adolescents (Kotler \& McMahon, 2005). The APSD-SR is a self-report version for 10- to 18-year-old youth, and it is based on the initial APSD available for parents and teachers of a child aged 6-13 years. The factorial validity of the instrument was previously examined using the same data sample as in this study, and a 3-factor model was found to best fit the data from Finnish adolescents, including an 8-item narcissism, a 5-item impulsivity, and a 4-item callous-unemotional subfactor (Laajasalo et al., 2014). A more detailed description of the factor analyses is given elsewhere (a reference identifying one of the authors). The APSD-SR yields a total score for the measure when the scores from all 20 items are summed together. Based on the current literature, no explicit cut-offs for total score of APSD-SR, nor for the parent or teacher version of APSD, have been established for differentiating adolescents with elevated levels of psychopathic features from those with low levels or an absence of these features. Furthermore, current empirical evidence suggests that psychopathic features among youth are best understood as a continuum along which every youth is situated, i.e. having more of less of these features, and therefore, psychopathy-like personality features should be conceptualized as a dimensional rather than a taxonic construct (Murrie et al., 2007). A continuous measure of the APSD-SR total score was therefore chosen to reflect psychopathic features.

\subsubsection{Independent variable.}

2.2.2.1. Victimization. The FSRD-12 survey included ten items measuring different types of victimization experiences. The participant was asked whether he/she had ever (at some point in life) experienced the type of victimization in question, e.g. "Has someone ever physically attacked you (e.g. hit, kicked, or used any weapon)? (Yes/No)". If the participant had answered "Yes", then an additional question of whether it had happened within the last 12 months was posed. A sum variable of ten items was formed by adding up the responses (Cronbach's $\alpha=0.74$ ). Supplementary Table 1 presents the ten victimization items in more detail.

\subsubsection{Control variables.}

2.2.3.1. Family structure. The FSRD-12 survey included a following item regarding the participant's family structure: "With whom do you live?" The response options were a) "with my mother and father", b) "partly with my mother, partly with my father", c) "only with my mother", d) "only with my father", e) "with my mother and her spouse/my stepfather", f) "with my father and his spouse/my stepmother", g) "with other relatives", h) "in a foster family", and i) "in another situation". A dichotomous measure was formed ( 1 = living with both biological parents, $0=$ not living with both biological parents) to reflect a nuclear family structure.

2.2.3.2. Family income. In the FSRD-12 survey, the participant was asked to compare the financial situation of the participant's family with that of the participant's acquaintance families using a 7-point Likert-scale (from $1=\mathrm{a}$ lot worse to $7=\mathrm{a}$ lot better). In the survey, this item was the only one that reflected SES of the family, and therefore, this measure was used in our analyses to represent the family income.

\subsection{Statistical analyses}

Differences between boys and girls were tested with Independent Samples T-test, Mann-Whitney $U$ test, and Chi-square test when appropriate. Associations between victimization and psychopathic features were assessed with linear regression. For victimization measures, two different time-frames were formed: 1 ) victimization at some point in life (coded as lifetime victimization), and 2) victimization experienced in the last 12 months (coded as recent victimization). This enabled us to examine how psychopathic features would relate to a) lifetime victimization (i.e. at some point in life), and b) recent victimization (i.e. in the last 12 months). We first assessed the bivariate associations between victimization and psychopathic features by setting the APSR total score as a dependent variable and a sum score of victimization variable as an independent variable. The models were first run for the total sample (adjusted for gender and age), and then separately for boys and girls 
Table 1

Descriptive statistics of study variables.

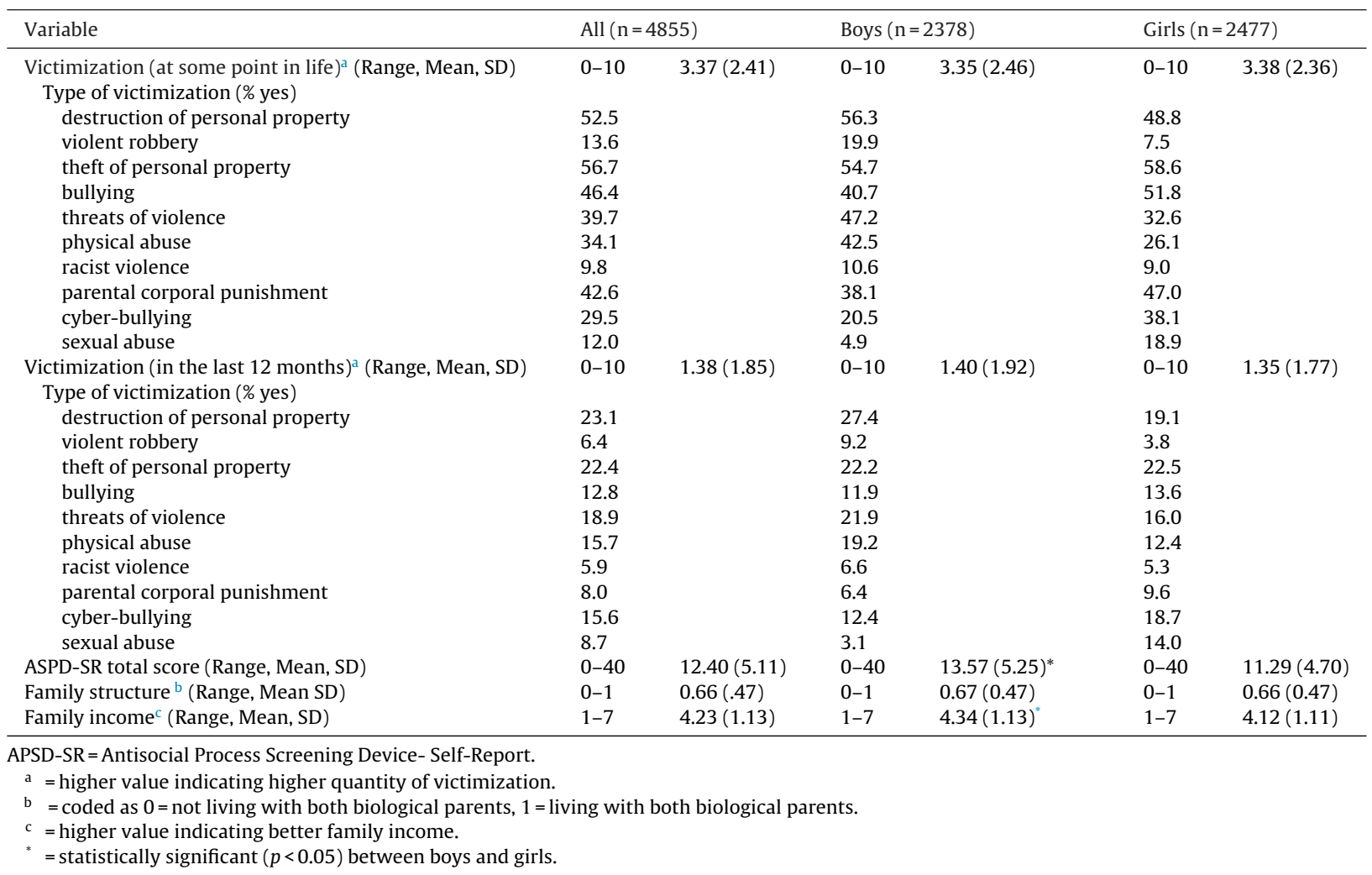

(adjusted for age), and statistical significance between boys and girls assessed by including an interaction term (victimization*gender regressed on APSD-SR total scores). Next, the models were further adjusted for family structure and income (multivariate model). The data were analyzed using IBM SPSS version 22. During all analyses appropriate sample weights were used to ensure that the sample was representative of Finnish adolescents (Laajasalo et al., 2014).

\section{Results}

\subsection{Descriptive results}

Table 1 displays the descriptive data of the study variables. Adolescents $(n=4855)$ reported that they had experienced several types of victimization in their lifetime (mean 3.4, SD 2.4). There was no gender difference in the average number of victimization experiences. Boys had higher APSD-SR total scores than girls (13.57 vs. $11.29, \mathrm{t}(38.03)=15.94, p<0.001)$.

\subsection{Associations between victimization and APSD-SR total scores}

Reported lifetime victimization (at some point in life) predicted APSD-SR total scores, both in total sample, and when models were run separately for boys and girls (Fig. 1, Table 2): a higher number of different types of victimization experiences was associated with higher total scores of APSD-SR. The linear trend showed that APSD-SR total scores increased by 1.05 points per number of victimization experiences. The association between victimization and APSD-SR total scores was stronger for girls than for boys $(p<0.001)$; the linear trend showed that APSD-SR total scores increased by 1.24 points per number of victimization experiences in girls, whereas in boys the linear trend was 0.87 points per number of victimization experiences (Table 2). The results remained significant and attenuated very little in multivariate models (see Supplementary Table 2 for multivariate models).

When the recent victimization experiences were explored, a statistically significant association was found between victimization and APSD-SR total scores: the higher the number of different types of recent victimization experiences, the higher the APSD-SR total scores (Table 2). The linear trend showed that APSD-SR total scores increased by 1.50 points per number of victimization experiences. No statistically significant difference in linear trend was found between boys and girls. The results remained significant and attenuated very little in multivariate models (see Supplementary Table 2 for multivariate models). 


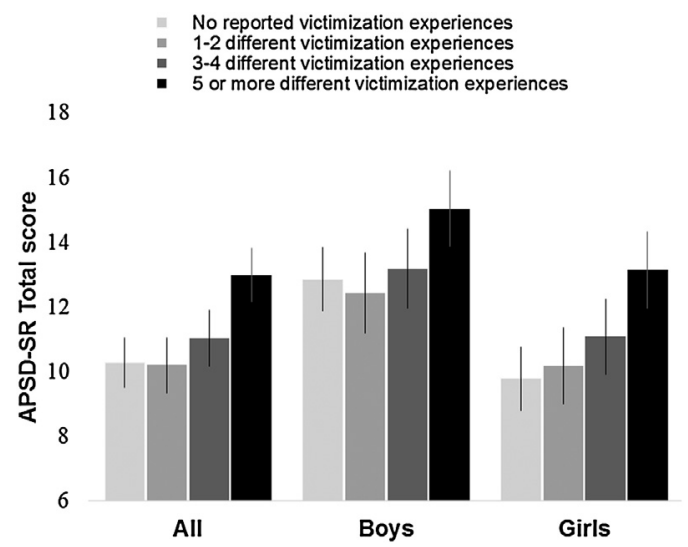

Fig. 1. Association between lifetime (at some point in life) victimization and APSD-SR total scores in the total sample, in boys and girls. Error bars are $95 \%$ confidence intervals. See Table 2 for statistical details. APSD-SR = Antisocial Process Screening Device- Self-Report.

Table 2

Linear regression models of lifetime (at some point in life) and recent (in the last 12 months) victimization predicting APSD-SR total scores.

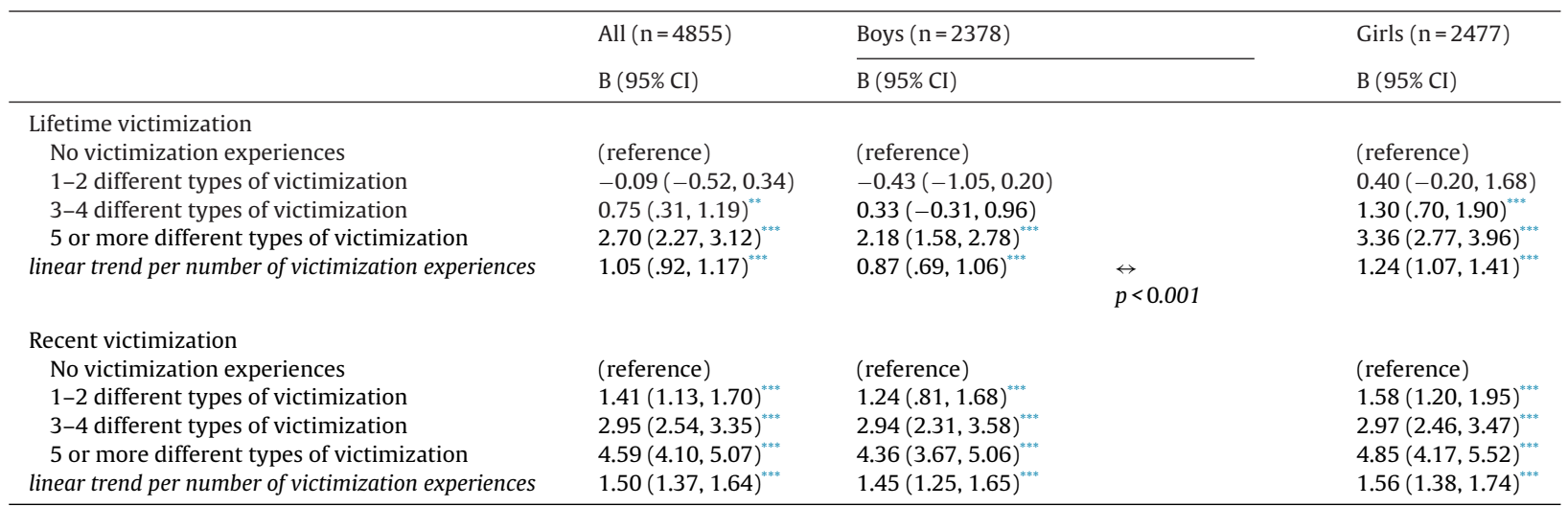

APSD-SR = Antisocial Process Screening Device- Self-Report. The models are adjusted for age, and All also for gender.

$* p<0.05$

${ }^{* *} p<0.01$.

*** $p<0.001$

Since the linear trend for victimization predicting APSD-SR total scores was higher for recent victimization (as indicated by non-overlapping point estimates and confidence intervals), the specific types of recent victimization experiences were then examined. Having experienced sexual abuse or parental corporal punishment in the last 12 months, were the strongest predictors of higher APSD-SR total scores in the GLM models (see Table 3). When the models were run separately for boys and girls, these two types of victimization experiences were also the strongest predictors of higher APSD-SR total scores (see Supplementary Table 3).

\section{Discussion}

This study examined victimization in relation to psychopathic features in a community-based sample of youth. The findings of the study add to the existing literature in many ways as the amount, severity, and timing of victimization, and the effect of gender were taken into account. We found that victimization experiences were significantly associated with psychopathic features in adolescents, more strongly in girls than in boys. In addition, especially recent experiences of victimization showed significance in the relationship between victimization and psychopathic features.

Our results showed that the more the adolescent had experienced victimization, the higher the APSD-SR total scores were. Concurrent with the prior research (Campbell et al., 2004; Docherty et al., 2015; Fanti \& Kimonis, 2012; Fanti et al., 2013; Kimonis et al., 2014; Krischer \& Sevecke, 2008; Odgers et al., 2005; Pardini \& Loeber, 2008), the finding suggest a link between victimization and juvenile psychopathic features. In community-based samples of adolescents, experiences of bullying (Fanti \& Kimonis, 2012; Fanti et al., 2013) and negative life events (Kimonis et al., 2014; Pardini \& Loeber, 2008), and exposure to aggression and violence (Docherty et al., 2015) have been associated with psychopathic features. In addition, severely abused juvenile offenders score high on psychopathy measures (Campbell et al., 2004; Krischer \& Sevecke, 2008; Odgers et al., 2005). However, some contradictory findings also exist (Hemphala, Kosson, Westerman, \& Hodgins, 2015). By 
Table 3

Linear regression models of different type of recent (in the last 12 months) victimization predicting APSD-SR total scores in the total sample ( $\mathrm{n}=4855$ )

\begin{tabular}{lll}
\hline & Univariate & Multivariate \\
\hline Type of victimization ${ }^{\mathrm{a}}$ & $\mathrm{B}(95 \% \mathrm{CI})$ & $\mathrm{B}(95 \% \mathrm{CI})$ \\
Destruction of personal property & $1.70(1.39-2.02)^{* * *}$ & $0.40(0.07-0.73)^{*}$ \\
Violent robbery $_{\text {Theft of personal property }}^{* * * *}$ & $0.67(0.08-1.25)^{*}$ \\
Bullying & $3.31(2.77-3.84)^{* * *}$ & $0.71(0.37-1.04)^{* * *}$ \\
Threats of violence & $1.97(1.66-2.28)^{* * * *}$ & $0.10(-0.50$ to 0.30$)$ \\
Physical abuse & $1.16(0.77-1.56)^{* * *}$ & $0.89(0.49-1.29)^{* * *}$ \\
Racist violence & $2.70(2.37-3.03)^{* * *}$ & $1.12(0.70-1.54)^{* * *}$ \\
Parental corporal punishment & $2.89(2.54-3.25)^{* * *}$ & $0.52(-0.06$ to 1.11$)$ \\
Cyber-bullying & $2.62(2.06-3.18)^{* * *}$ & $1.68(1.19-2.17)^{* * *}$ \\
Sexual abuse & $3.22(2.74-3.70)^{* * *}$ & $.58(0.19-0.96)^{* *}$ \\
\hline
\end{tabular}

APSD-SR = Antisocial Process Screening Device- Self-Report. Univariate = adjusted for age and gender, Multivariate = adjusted for age, gender and all other victimization experiences.

a Each item is coded as $0=$ No, $1=$ Yes .

* $p<0.05$.

** $p<0.01$.

** $p<0.001$.

assessing a sample of adolescents from juvenile substance misuse clinic, Hemphala et al. (2015) reported that childhood physical abuse was not associated with PCL-R scores in youth. Our study contributes to the present literature by showing that severe forms of victimization experiences (i.e. physical and sexual abuse) are strongly associated with psychopathic features also in community youth. Interestingly, we also found a strong association between parental corporal punishment and psychopathic features in this community sample of adolescents. This highlights the risk effects of physical punishment for adolescents' behavioral and social functioning, not only internalizing problems (Ma, Han, Grogan-Kaylor, Delva, \& Castillo, 2012).

The present study found that victimization experiences were related to higher APSD-SR total scores, both in boys and girls. Only a few previous studies have examined psychopathic features in abused or victimized youth samples including also girls. Odgers et al. (2005) found that victimization experiences were moderately associated with psychopathic features in juvenile female offenders. By evaluating boys and girls separately, Krischer and Sevecke (2008) reported that childhood abuse (including physical and sexual abuse) was related to psychopathic features in juvenile offenders, but mainly in boys. Fanti and Kimonis (2012), on the other hand, did not find any gender differences in the link between being a victim of bullying and psychopathic features in sample of school adolescents. We observed that the association between victimization and psychopathic features was stronger for girls than for boys. The differences in the type of victimization experiences (i.e. bullying vs. more severe victimization such as physical and sexual abuse) and sample types (community vs. offender samples) might explain the mixing results of previous studies and the present study. The present study discloses novel information on how severe victimization experiences are associated with psychopathic features in community girls. Having said this, the association between victimization and psychopathic features was stronger for girls than boys but only for lifetime, not recent, victimization. It is possible childhood abuse and maltreatment contributes to increase in psychopathic features more strongly in girls than boys. These findings highlight the need for more research on how victimization experiences are related to psychopathic features in girls. Future longitudinal investigations would elucidate if victimized or abused girls might be particularly vulnerable to developing psychopathic features.

Interestingly, recent victimization showed significance in the association between victimization and psychopathic features. One possible explanation for this finding could be that experiences of victimization may contribute to emotional "numbing" as a means of self-protection, e.g. trying to avoid awareness of distressing emotions (Kalisch et al., 2005). Furthermore, the emotional numbing resulting from posttraumatic events may lead to reduction of both empathy towards others and inhibitions against antisocial behavior (Lansford et al., 2002). Bennet and Kerig (2014) found that youth high on callous-unemotional (CU) traits can be differentiated on the basis of posttraumatic stress symptoms (PTSS), with one group ("acquired" CU, referring to secondary psychopathy) reporting significantly higher levels of PTSS symptoms than the other group ("primary" CU) (Bennet \& Kerig, 2014). The acquired CU group also showed greater emotional numbing than the primary CU group. Some of the adolescents in our study may also have shown this emotional numbing, which, at least to some extent, was reflected in the APSD-SR measure as higher total scores. Furthermore, for some of the adolescents, psychopathic tendencies may be temporary, stemming from the need to develop coping strategies. We found that specifically adolescents who had recently experienced sexual abuse or parental corporal punishment scored higher on APSD-SR total scores. Adolescents who experience severe forms of victimization might use emotional numbing as a way to survive trauma, with this manifesting as psychopathic tendencies (Odgers et al., 2005; Porter, 1996). For recent victimization, there were no gender differences, suggesting that adolescent girls and boys may show similar "reactive behavior style", resembling psychopathic features, to recent experiences of victimization.

It is also possible that the behavior of adolescents who manifest psychopathic features may provoke others to mistreat the adolescent in kind. For example, in adults, narcissistic features have been shown to be associated with victimization (McCullough, Emmons, Kilpatrick, \& Mooney, 2003; Rhodewalt, Madrian, \& Cheney, 1998). McCullough et al. (2003) hypoth- 
esized that narcissistic people might behave in a way that generates negative reactions and negative behaviors from others. Narcissistic people may also perceive themselves as "victims" of other people's mistreatment to bolster their self-esteem. Furthermore, some researchers have suggested that individuals with CU traits could evoke more negative life events from their environments because of their characteristics, such as their tendency to seek out novel and stimulating experiences (Kandler, Bleidorn, Riemann, Angleitner, \& Spinath, 2012; Kimonis et al., 2014). Research has also shown that adolescents with CU traits are prone to arouse more harsh and inconsistent discipline from their parents over time than do adolescents without these traits (Hawes, Dadds, Frost, \& Hasking, 2011; Munoz, Pakalniskiene, \& Frick, 2011). As suggested by Kimonis et al. (2014), abusive experiences may influence the development of CU traits which, in turn, increase the risk of victimization. Because our study was cross-sectional, no interpretation of the cause and effect can be made. More longitudinal studies (e.g. Kimonis et al., 2014) are needed to evaluate whether adolescents with a history of abuse who start showing psychopathic features are actually victimized more because of their psychopathic behavior style.

When interpreting the findings of the present study, it should be considered that there might be a subgroup of adolescents who reported recent experiences of victimization but who also have had earlier experiences of victimization. For example, parental corporal punishment is likely to be nested within an overall context of constant parenting (Ma et al., 2012), thus reflecting a more pervasive and long-lasting authoritarian style of parenting. Nevertheless, even infrequent parental corporal punishment has been associated with antisocial behavior in children and adolescents (Grogan-Kaylor, 2004; Ma et al., 2012). Thus, the findings of the present study could possibly suggest that juvenile psychopathic tendencies can reflect person's coping styles to a new, recent trauma, but not necessarily the development of psychopathy. And yet, in some youth, the psychopathic features reflect a more constant behavior style resulting from long-term and ongoing victimization, and these youths are in real risk of developing psychopathy in adulthood. Obviously, to disentangle these questions, longitudinal studies are needed in which the effects of abuse and maltreatment are assessed at different time-points in childhood and adolescence, in addition to examining how the timing of the victimization is related to psychopathic features in these two subject groups.

Several limitations of this study must be addressed. First, all data used were based on adolescent self-report, which carries the risk of under-reporting or over-reporting, and the associations could have been inflated due to shared method variance. The questionnaire was, however, completed anonymously and participation was voluntary, thus minimizing the motivation to misreport. Furthermore, the reliability and validity of self-reports assessing psychopathology, especially maladaptive affective styles that are not always evident, have been shown to increase in adolescence (Kamphaus \& Frick, 1996). Many studies provide support for the reliability and validity of self-report in adolescent psychopathy research (Munoz \& Frick, 2007; Vahl et al., 2014; Vaughn, Howard, \& Delisi, 2008). However, we used information from only one respondent to assess psychopathic features, and this is our study's major shortcoming. Although self-reports are easy and economical to use, the assessment of psychopathic features in adolescents cannot rely solely on self-reports, rather the assessment should include multiple assessment methods and information from multiple respondents (e.g. self-report, parent and teacher reports, clinical interviews). For example, grandiosity and self-centeredness may be part of normative adolescent development (Seagrave \& Grisso, 2002), and clinical interviews allow for a more detailed clarification and elaboration of these traits. Second, we investigated the association between victimization experiences and psychopathic features in youth using only APSD-SR total scores, and therefore, the results must be interpreted cautiously. Third, the sample comprised solely 15- to 16-year-old adolescents, thus limiting the generalization of the findings to other age groups. Finally, because the study was cross-sectional, causal conclusions regarding victimization and psychopathic features in youth cannot be drawn.

Notwithstanding the limitations, the study also has many strengths. A major advantage lies in the large sample size of community youth. Our study discloses novel findings on how severe forms of victimization experiences relate to psychopathic features in community adolescents, especially in girls. Very few studies exist regarding the relationship between severe victimization and psychopathic features in adolescents, and the samples have solely consisted of offenders. The present study adds to previous research by extending the research into community-based adolescents, which is essential to the goal of distinguishing normative adolescent features from those more consistent with the features of psychopathy (Campbell et al., 2004). We also examined the relationship between very recent victimization and psychopathic features in youth, thus diminishing the risk that individuals may not remember events occurring long ago, a shortcoming of many previous studies (Saunders \& Adams, 2014).

The findings of the present study suggest that adolescents showing psychopathic features have experienced victimization. When psychopathic features are present in youth (especially in girls), it is essential to evaluate the adolescent's psychosocial situation in a comprehensive manner, taking into account possible history of and ongoing victimization and trauma. The use of structured questionnaire or interview about victimization experiences may help in identifying these experiences. Of note is, that also adolescents may be exposed to corporal punishment by parents. Prevention and recognition of victimization may be important in reducing psychopathic features in youth. Psychoeducation for parents and community workers about the high frequency of victimization experiences in adolescents and about the correlates of these experiences may help in prevention efforts. Follow-up studies are needed to determine the causal relationships between the victimization experiences and psychopathic features.

\section{Conflict of interest}

None declared. 


\section{Acknowledgements}

This study was supported by the grants of Helsinki University Hospital Research Grants, Foundation for Pediatric Research, Emil Aaltonen Foundation, and Päivikki and Sakari Sohlberg Foundation.

\section{References}

Abram, K. M., Teplin, L. A., Charles, D. R., Longworth, S. L., McClelland, G. M., \& Dulcan, M. K. (2004). Posttraumatic stress disorder and trauma in youth in juvenile detention. Archives of General Psychiatry, 61, 403-410. http://dx.doi.org/10.1001/archpsyc.61.4.403

Bennet, D. C., \& Kerig, P. K. (2014). Investigating the construct of trauma-related acquired callousness among delinquent youth: differences in emotion processing. Journal of Traumatic Stress, 27, 415-422. http://dx.doi.org/10.1002/jts.21931

Blair, R. J., Peschardt, K. S., Budhani, S., Mitchell, D. G., \& Pine, D. S. (2006). The development of psychopathy. Journal of Child Psychology and Psychiatry, and Allied Disciplines, 47, 262-276. http://dx.doi.org/10.1111/j.1469-7610.2006.01596.x

Campbell, M. A., Porter, S., \& Santor, D. (2004). Psychopathic traits in adolescent offenders: an evaluation of criminal history, clinical, and psychosocial correlates. Behavioral Sciences \& the Law, 22, 23-47. http://dx.doi.org/10.1002/bsl.572

Cauffman, E., Feldman, S. S., Waterman, J., \& Steiner, H. (1998). Posttraumatic stress disorder among female juvenile offenders. Journal of the American Academy of Child and Adolescent Psychiatry, 37, 1209-1216.

Chamberlain, P., \& Moore, K. J. (2002). Chaos and trauma in the lives of adolescent females with antisocial behavior and delinquency. Journal of Aggression, Maltreatment E'Trauma, 6, 79-108. http://dx.doi.org/10.1300/J146v06n01_05

Dixon, A., Howie, P., \& Starling, J. (2004). Psychopathology in female juvenile offenders. Journal of Child Psychology and Psychiatry, and Allied Disciplines, 45, 1150-1158. http://dx.doi.org/10.1111/j.1469-7610.2004.00307.x

Docherty, M., Boxer, P., Huesmann, L. R., O’Brien, M., \& Bushman, B. J. (2015). Exploring primary and secondary variants of psychopathy in adolescents in detention and in the community. Journal of Clinical Child and Adolescent Psychology, (January), 1-15. http://dx.doi.org/10.1080/15374416.2014.979934, 20, [Epub ahead of print]

Fanti, K. A., \& Kimonis, E. R. (2012). Bullying and victimization: the role of conduct problems and psychopathic traits. Journal of Research on Adolescence, 22, 617-631. http://dx.doi.org/10.1111/j.1532-7795.2012.00809.x

Fanti, K. A., Demetriou, C. A., \& Kimonis, E. R. (2013). Variants of callous-unemotional conduct problems in a community sample of adolescents. Journal of Youth and Adolescence, 42, 964-979. http://dx.doi.org/10.1007/s10964-013-9958-9

Forth, A. E., Kosson, D. S., \& Hare, R. D. (2003). Psychopathy checklist: Youth version (PCL-YV). Toronto, Ontario, Canada: Multi-Health Systems.

Frick, P. J., \& Hare, R. D. (2001). Antisocial process screening device (APSD) (1. th ed.). Canada: Multi-Health Systems Inc.

Gao, Y., Raine, A., Chan, F., Venables, P. H., \& Mednick, S. A. (2010). Early maternal and paternal bonding, childhood physical abuse and adult psychopathic personality. Psychological Medicine, 40,1007-1016. http://dx.doi.org/10.1017/S0033291709991279

Grogan-Kaylor, A. (2004). The effect of corporal punishment on antisocial behavior in children. Social Work Research, 28, $153-162$. http://dx.doi.org/10.1093/swr/28.3.153

Hare, R. D. (1991). The hare psychopathy checklist-revised (1st ed.). Toronto: Multi-Health Systems.

Hawes, D. J., Dadds, M. R., Frost, A. D., \& Hasking, P. A. (2011). Do childhood callous-unemotional traits drive change in parenting practices? Journal of Clinical Child and Adolescent Psychology, 40,507-518. http://dx.doi.org/10.1080/15374416.2011.581624

Hemphala, M., \& Hodgins, S. (2014). Do psychopathic traits assessed in mid-adolescence predict mental health, psychosocial, and antisocial, including criminal outcomes, over the subsequent 5 years? Canadian Journal of Psychiatry. Revue Canadienne De Psychiatrie, 59, 40-49.

Hemphala, M., Kosson, D., Westerman, J., \& Hodgins, S. (2015). Stability and predictors of psychopathic traits from mid-adolescence through early adulthood. Scandinavian Journal of Psychology, 56, 649-658. http://dx.doi.org/10.1111/sjop.12257

Hicks, B. M., Markon, K. E., Patrick, C. J., Krueger, R. F., \& Newman, J. P. (2004). Identifying psychopathy subtypes on the basis of personality structure. Psychological Assessment, 16, 276-288. http://dx.doi.org/10.1037/1040-3590.16.3.276

Hicks, B. M., Vaidyanathan, U., \& Patrick, C. J. (2010). Validating female psychopathy subtypes: Differences in personality, antisocial and violent behavior, substance abuse, trauma, and mental health. Personality Disorders, 1, 38-57. http://dx.doi.org/10.1037/a0018135

Kalisch, R., Wiech, K., Critchley, H. D., Seymour, B., O’Doherty, J. P., Oakley, D. A., . . \& Dolan, R. J. (2005). Anxiety reduction through detachment: Subjective, physiological, and neural effects. Journal of Cognitive Neuroscience, 17, 874-883. http://dx.doi.org/10.1162/0898929054021184

Kamphaus, R. W., \& Frick, P. J. (1996). Clinical assessment of child and adolescent personality and behavior. Boston: Allyn and Bacon.

Kandler, C., Bleidorn, W., Riemann, R., Angleitner, A., \& Spinath, F. M. (2012). Life events as environmental states and genetic trais and the role of personality: A longitudinal twin study. Behavior Genetics, 42, 57-72. http://dx.doi.org/10.1007/s10519-011-9491-0

Karpman, B. (1941). On the need of separating psychopathy into two distinct clinical types: The symptomatic and the idiopathic. Journal of Criminology and Psychopathology, 3, 112-137.

Karpman, B. (1948). Concience in the psychopath: Another version. American Journal of Orthopsychiatry, 18, 455-491.

Kimonis, E. R., Skeem, J. L., Cauffman, E., \& Dmitrieva, J. (2011). Are secondary variants of juvenile psychopathy more reactively violent and less psychosocially mature than primary variants? Law and Human Behavior, 35, 381-391. http://dx.doi.org/10.1007/s10979-010-9243-3

Kimonis, E. R., Cross, B., Howard, A., \& Donoghue, K. (2013). Maternal care, maltreatment and callous-unemotional traits among urban male juvenile offenders. Journal of Youth and Adolescence, 42, 165-177. http://dx.doi.org/10.1007/s10964-012-9820-5

Kimonis, E. R., Centifanti, L. C., Allen, J. L., \& Frick, P. J. (2014). Reciprocal influences between negative life events and callous-unemotional traits. Journal of Abnormal Child Psychology, 42, 1287-1298. http://dx.doi.org/10.1007/s10802-014-9882-9

Kivivuori, J., \& Bernburg, J. G. (2011). Delinquency research in the Nordic countries. In M. Tonry, \& T. Lappi-Seppälä (Eds.), Crime and justice in Scandinavia (pp. 405-478). Chicago: University of Chicago Press.

Kotler, J. S., \& McMahon, R. J. (2005). Child psychopathy: Theories, measurement, and relations with the development and persistence of conduct problems. Clinical Child and Family Psychology Review, 8, 291-325. http://dx.doi.org/10.1007/s10567-005-8810-5

Krischer, M. K., \& Sevecke, K. (2008). Early traumatization and psychopathy in female and male juvenile offenders. International Journal of Law and Psychiatry, 31, 253-262. http://dx.doi.org/10.1016/j.ijlp.2008.04.008

Laajasalo, T., Saukkonen, S., Kivivuori, J., Salmi, V., Lipsanen, J., \& Aronen, E. T. (2014). Brief report: self-reported psychopathic-like features among Finnish community youth: investigation of the factor structure of the antisocial personality screening device. Journal of Adolescence, $37,1185-1188$. http://dx.doi.org/10.1016/j.adolescence.2014.08.010

Lansford, J. E., Dodge, K. A., Pettit, G. S., Bates, J. E., Crozier, J., \& Kaplow, J. (2002). A 12-year prospective study of the long-term effects of early child physical maltreatment on psychological, behavioral, and academic problems in adolescence. Archives of Pediatrics $\mathcal{E}$ Adolescent Medicine, 156, 824-830 [poa20065].

Loeber, R., Burke, J., \& Pardini, D. A. (2009). Perspectives on oppositional defiant disorder, conduct disorder, and psychopathic features. Journal of Child Psychology and Psychiatry, and Allied Disciplines, 50, 133-142. http://dx.doi.org/10.1111/j.1469-7610.2008.02011.x

Ma, J., Han, Y., Grogan-Kaylor, A., Delva, J., \& Castillo, M. (2012). Corporal punishment and youth externalizing behavior in Santiago, Chile. Child Abuse E Neglect, 36, 481-490. http://dx.doi.org/10.1016/j.chiabu.2012.03.006

McCullough, M. E., Emmons, R. A., Kilpatrick, S. D., \& Mooney, C. N. (2003). Narcissists as victims: The role of narcissism in the perception of transgressions. Personality E' Social Psychology Bulletin, 29, 885-893. http://dx.doi.org/10.1177/0146167203029007007 
Munoz, L. C., \& Frick, P. J. (2007). The reliability, stability, and predictive utility of the self-report version of the antisocial process screening device. Scandinavian Journal of Psychology, 48, 299-312 [SJOP560].

Munoz, L. C., Pakalniskiene, V., \& Frick, P. J. (2011). Parental monitoring and youth behavior problems: Moderation by callous-unemotional traits over time. European Child E'Adolescent Psychiatry, 20, 261-269. http://dx.doi.org/10.1007/s00787-011-0172-6

Murrie, D. C., Marcus, D. K., Douglas, K. S., Lee, Z., Salekin, R. T., \& Vincent, G. (2007). Youth with psychopathy features are not a discrete class: A taxometric analysis. Journal of Child Psychology and Psychiatry, and Allied Disciplines, 48, 714-723 [JCPP1734].

Odgers, C. L., Reppucci, N. D., \& Moretti, M. M. (2005). Nipping psychopathy in the bud: An examination of the convergent, predictive, and theoretical utility of the PCL-YV among adolescent girls. Behavioral Sciences and the Law, 23, 743-763. http://dx.doi.org/10.1002/bsl.664

Pardini, D. A., \& Loeber, R. (2008). Interpersonal Callousness Trajectories Across Adolescence: Early social influences and adult outcomes. Criminal Justice and Behavior, 35, 173-196. http://dx.doi.org/10.1177/0093854807310157

Porter, S. (1996). Without conscience or without active conscience? The etiology of psychopathy revisited. Aggresion and Violent Behavior, 3, 303-338.

Poythress, N. G., \& Skeem, J. L. (2005). Disaggregating psychopathy: Where and how to look for variants. In C. J. Patrick (Ed.), Handobook of psychopathy (pp. 172-192). New York: Guilford Press.

Rhodewalt, F., Madrian, J. C., \& Cheney, S. (1998). Narcissism, self-knowledge organization: And emotional reactivity: The effect of daily experiences on self-esteem and affect. Personality E' Social Psychology Bulletin, 24, 75-87.

Rubio, J. S., Krieger, M. A., Finney, E. J., \& Coker, K. L. (2014). A review of the relationship between sociocultural factors and juvenile psychopathy. Aggression and Violent Behavior, 19, 23-31. http://dx.doi.org/10.1015/j.avb.2013.11.001

Salmi, V. (2012). Nuorten rikoskäyttäytyminen ja uhrikokemukset. (Self-reported juvenile delinquency and victimization in Finland), Oikeuspoliittisen tutkimuslaitoksen tutkimustiedonantoja, 2012,113, Helsinki. Retrieved from https://helda.helsinki.fi/bitstream/handle/10138/152500/tta_113_Salmi.pdf? sequence=1.

Saunders, B. E., \& Adams, Z. W. (2014). Epidemiology of traumatic experiences in childhood. Child and Adolescent Psychiatric Clinics of North America, 23, 167-184. http://dx.doi.org/10.1016/j.chc.2013.12.003 [vii]

Seagrave, D., \& Grisso, T. (2002). Adolescent development and the measurement of juvenile psychopathy. Law and Human Behavior, $26,219-239$.

Skeem, J. L., Poythress, N. G., Edens, J. F., Lilienfeld, S. O., \& Cale, E. (2003). Psychopathic personality or personalities? Exploring potential variants of psychopathy and their implications for risk assessment. Aggression and Violent Behavior, 8, 513-546. http://dx.doi.org/10.1016/S1359-1789(02)00098-8

Skeem, J., Johansson, P., Andershed, H., Kerr, M., \& Louden, J. E. (2007). Two subtypes of psychopathic violent offenders that parallel primary and secondary variants. Journal of Abnormal Psychology, 116, 395-409 [2007-06673-015].

Tatar, J. R., Cauffman, E., Kimonis, E. R., \& Skeem, J. L. (2012). Victimization history amd post-traumatic stress: An analysis of psychopathy variants in male juvenile offenders. Journal of Child and Adolescent Trauma, 5, 102-113. http://dx.doi.org/10.1080/19361521.2012.671794

Vahl, P., Colins, O. F., Lodewijks, H. P., Markus, M. T., Doreleijers, T. A., \& Vermeiren, R. R. (2014). Psychopathic-like traits in detained adolescents: Clinical usefulness of self-report. European Child E'Adolescent Psychiatry, 23, 691-699. http://dx.doi.org/10.1007/s00787-013-0497-4

Vaughn, M. G., Howard, M. O., \& Delisi, M. (2008). Psychopathic personality traits and delinquent careers: An empirical examination. International Journal of Law and Psychiatry, 31, 407-416. http://dx.doi.org/10.1016/j.ijlp.2008.08.001

Vaughn, M. G., Edens, J. F., Howard, M. O., \& Smith, S. T. (2009). An investigation of primary and secondary psychopathy in a statewide sample of incarcerated youth. Youth Violence and Juvenile Justice, 7, 172-188. http://dx.doi.org/10.1177/1541204009333792

\section{Appendix A. Supplementary data}

Supplementary data associated with this article can be found, in the online version, at http://dx.doi.org/10.1016/j.chiabu.2016.09.008. 